\title{
ORIGINAL ARTICLE QUALITY OF LIFE AFTER PRIMARY PCI IN PAKISTANI POPULATION - DOES IT REALLY CHANGE?
}

\author{
Rajesh Kumar'1, Ali Ammar¹, Jehangir Ali Shah'1, Tahir Saghir ${ }^{1}$, Ashok Kumar'1, Abdul \\ Hakeem Shaikh ${ }^{1}$, Musa Karim ${ }^{1}$, Jawaid Akbar Sial ${ }^{1}$, Lajpat Rai ${ }^{2}$, Abdul Hafeez ${ }^{1}$, Dileep \\ Kumar $^{1}$ \\ ${ }^{1}$ National Institute of Cardiovascular Diseases, Karachi, Pakistan, ${ }^{2}$ National Institute of Cardiovascular Diseases, Hyderabad, Pakistan
}

\begin{abstract}
Objectives: To evaluate the quality of life (QOL) after percutaneous coronary intervention (PCI) using short-form health survey (SF-36) questionnaire at a tertiary care hospital in Pakistan.

Methodology: It was a cross-sectional study conducted at a tertiary care cardiac center in Pakistan. A total of 433 adult patients who undergone PCI at least six months before were included. The QOL was assessed using Urdu translated version of SF-36 questionnaire. QOL scores were computed on eight domains role physical (RP), role emotional (RE), bodily pain (BP), physical function (PF), mental health (MH), vitality, general health perception (GHP), and social function (SF) along with two summary scores for mental (MCS) and physical component (PPS).

Results: The highest mean score was reported for BP $(73.8 \pm 19.7)$ followed by PF $(61.7 \pm 24.3)$. In comparison to a year before, $52.9 \%$ and $24.7 \%$ rated their QOL somewhat better and much better respectively. Score for PF, RE, and RF were significantly higher in male, while, vitality was higher for female. Score of PPS was significantly higher for male whereas MCS score was higher for female. An increasing trend, with respect to patients' perception of QOL compared to an year ago, was observed on five out of eight domains namely GHP, PF, RP, RE, and BP. Conclusion: Improved QOL, compared to a year ago, is reported by most of the patients. An acceptable $(>50)$ mean score was observed on most of the QOL domains of SF-36 and it was found to be positively related to the patient stated degrees of QOL.
\end{abstract}

Keywords: coronary artery disease, cardiac disease, percutaneous coronary intervention, quality of life, physical health, mental health, short-form health survey

Citation: Kumar R, Ammar A, Shah JA, Saghir T, Kumar A, Shaikh AH, Karim M, Sial JA, Rai L, Hafeez A, Kumar D. Quality of Life after Primary PCI in Pakistani Population - Does it Really Change?. Pak Heart J. 2021;54(03):224-

229. DOI: https://doi.org/10.47144/phj.v54i3.2164

\section{INTRODUCTION}

Nearly 18 million people died from cardiovascular diseases globally in 2015, accounting for 31 percent of global fatalities, including nearly seven million deaths due to coronary artery disease (CAD). ${ }^{1}$ Over the past decades, the fatality rate due to CAD in the western population has steadily declined, but still causes around one-third of all deaths in people over 35 years of age. ${ }^{2}$ Percutaneous coronary intervention (PCI) and coronary artery bypass graft surgery (CABG) are also highly frequent procedures because of the high prevalence of $\mathrm{CAD}^{3}$ In treating CAD, both approaches have proved to be safe and reliable. ${ }^{4}$ Several studies have shown decrease in mortality and greatly improved quality of life (QOL) by both CABG and PCI. However, in some frequently encountered health cases such as unprotected left main CAD, the choice of treatment between the two has remained unclear for a long time. ${ }^{4}$

Quality of life (QOL) expresses a person's subjective views on his or her position in the sense of living. ${ }^{5} \mathrm{In}$ patients seeking cardiac care, it is important to devote attention to QOL, as patients not only desire to live longer but also want to have better QOL. ${ }^{6}$ Another justification for assessing the QOL of cardiac patients is to assess the success of procedure in the patient's opinion. QOL assessment may also help in evaluating the physical and mental health status of patients. Like it includes problems related to day-to-day physical activities, limitations of role in society and the effect of pain on day-to-day functions. When these QOLrelated concerns are identified, techniques can be used to address these concerns in the outpatient management plan of the survived patients. Like it includes the decision regarding the duration of followup appointments and the option of patients to be followed up at the primary level health care facility. ${ }^{7}$

Questionnaires are the most popular method of measuring quality of life. On the basis of the literature, Gierlaszyńska $\mathrm{K}$ et al. ${ }^{3}$ concluded that the Short-Form Health Survey (SF-36) questionnaire is one of the most widely used tools measuring the quality of life of 
patients undergoing cardiological treatment and cardiac surgery. The SF-36 evaluates eight dimensions of health: physical functioning, role limitations due to physical problems, bodily pain, vitality, general health perception, social function, role limitations due to emotional problems, and mental health. ${ }^{8}$ In low- and middle-income countries like Pakistan, the differences in socio-demographic factors and social-culture context may have influence on health-related QOL (HRQOL).

PCI, especially primary PCI, has proven mortality and morbidity benefits in patients with CAD. Our institution, in collaboration with Provincial Government of Sindh, is providing 24/7 free of cost service to patients through its eight-satellite center across the province.

Despite huge number of procedures performed in recent years, post PCI quality of life has not been documented in our population. Monitoring of quality of life will not only help us to evaluate effectiveness in terms of better quality of life of patients but also channelize health resources for betterment of population. From a patient standpoint, alongside mortality and morbidity benefit, understanding of post procedure quality life and symptom relief may improve confidence level and influence their choice of revascularization strategy. Therefore, this research was designed with aim to explore the HRQOL in patients after percutaneous coronary intervention (PCI) and to validate Urdu translation of short-form health survey (SF-36) questionnaire at a tertiary care hospital in Karachi, Pakistan.

\section{METHODOLOGY}

It was a cross-sectional study conducted at the Outpatient Department (OPD) of a tertiary care cardiac center of Karachi, Pakistan from 1st of July 2019 to 31st December 2019. Patients of age above 18 years of either gender who undergone for PCI at least six months before and were presented in OPD for follow-up were included in the study. After the approval of ethical review committee of institution, required number patients who had fulfilled the inclusion criteria were enrolled. Verbal informed consent was taken by the principal investigator from all patients regarding their participation in the study and publication of concealed data. Patients with prior cardiac related surgery, chronic kidney diseases (CKD), congenital disease, left main disease, mental condition and any other health condition that required regular or occasional invasive medical therapy were excluded from the study. Data were collected using structured questionnaire covering demographic characteristics, predisposing risk factors and procedural details.

The quality of life was assessed using 36-item Short Form General Health Survey (SF-36) questionnaire. Considering the low literacy rate in our population, the SF-36 questionnaire was translated and validated in Urdu language. The steps involved in the translation and validation of SF-36 in Urdu language were as follow;

Step 1: Forward translation, the questionnaire was translated to Urdu by a bilingual professional translator with excellent proficiency in Urdu and English language. Idiomatic translation was encouraged rather than word-for-word translation.

Step 2: Backward translation, the Urdu translated questionnaire was back translated to English by another independent bilingual professional translators with excellent proficiency in Urdu and English language to verify whether or not the meaning of the items of the questionnaire were preserved. Shortcomings in translation, vocabulary, and cultural adaptations were identified and Urdu translated version of the SF-36 was finalized.

Step 3: Field test, Urdu translated version of SF-36 questionnaire was administrated on five randomly selected adult patients and they were asked to rate difficulty level in understanding or dealing with any item of the questionnaire on five-point scale, with 1 being "very easy to understand" and 5 being "very difficult to understand". Items with at least one 4 or 5 rating were reviewed by the expert in linguistics and modified accordingly.

Step 4: Reliability test, a randomly selected 30 adult patients were recruited for test-retest procedure to assess the reliability of translated version of SF-36 questionnaire. The Urdu translated version of SF-36 questionnaire was administered twice by the same investigator with a 7-day interval to avoid recall bias and changes in clinical status. The test-retest reliability measure, the Pearson Correlation Coefficient (PCC), was statistically significant with $\mathrm{p}<0.01$ and correlation coefficients $>0.80$ for all eight domains of the SF-36 questionnaire.

The eight domains of SF-36 were scored according to the standard scoring rules [9], for each of the eight domains, items were re-coded so that higher values indicate better quality of health, scores of the corresponding items were added to compute a domain score, and then the computed score was transformed to a zero to 100 range scale. In addition to the eight 
domains, two summary measures were also computed corresponding to mental (MCS) and physical component (PPS) with the help of factor analysis. The two summary scores were the weight average of domain using with the coefficient obtained in factor analysis, as presented in Table 1. Factor analysis was performed with "Principal Component Analysis" as extraction method and "Varimax" rotation with "Kaiser Normalization". Based on standard criteria of eigenvalue greater than one, a two factor solution was obtained with eigenvalues of 2.46 and 1.78 . The total cumulative variance explained by the two factor solution was $60.3 \%$.

The "social function" domain was excluded in the phase I of the factor analysis due to low communality value and final analysis was performed using eight domains. Communalities by eight domains of SF-36 and rotated component matrix of two component factor analysis solution are presented in Table 1 . In the two factor solution, four domains, namely role physical (RP), role emotional (RE), bodily pain (BP), and physical function (PF), loads onto the physical component $(\mathrm{C} 1)$ and remaining three domains, namely mental health $(\mathrm{MH})$, vitality, general health perception (GHP), were loads onto the mental component (C2). The component plot in rotated space is presented in Figure 1.

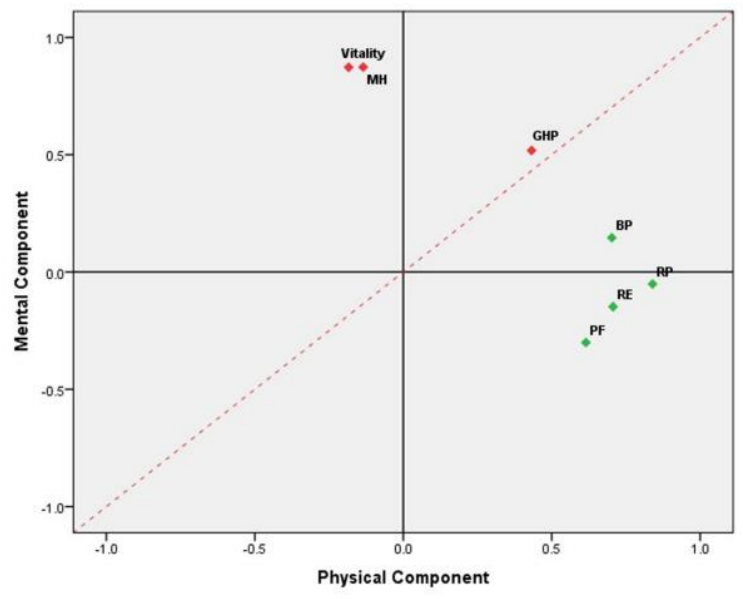

Figure 1: Component Plot in Rotated Space

$B P=$ bodily pain, $G H P=$ general health perception, $M H=$ mental health, $P F=$ physical function, $R E=$ role emotional, $R P=$ role physical, $S F=$ social function

The mental and physical component scores were computed as a weighted linear combination by taking sum-product of $\mathrm{z}$-score of the domain score and its corresponding component coefficient (as provided in Table 1) and computed scores were then transformed that the both components had mean of 50 and standard deviation of 10 .
Table 1: Communalities by eight domains of SF 36 and rotated component matrix of two component factor analysis solution

\begin{tabular}{l|c|c|c|c}
\hline \multirow{2}{*}{\begin{tabular}{l} 
Domains of SF- \\
\cline { 2 - 5 }
\end{tabular}} & \multicolumn{2}{|c|}{ Communalities } & \multicolumn{2}{c}{$\begin{array}{c}\text { Rotated Component } \\
\text { Matrix }\end{array}$} \\
\cline { 2 - 5 } & $\begin{array}{c}\text { Phase } \\
\text { I }\end{array}$ & $\begin{array}{c}\text { Phase } \\
\text { II }\end{array}$ & $\begin{array}{c}\text { C1: } \\
\text { Physical }\end{array}$ & $\begin{array}{c}\text { C2: } \\
\text { Mental }\end{array}$ \\
\hline $\begin{array}{l}\text { Role Physical } \\
\text { (RP) }\end{array}$ & 0.703 & 0.707 & $\mathbf{0 . 8 4 0}$ & -0.051 \\
\hline $\begin{array}{l}\text { Role Emotional } \\
\text { (RE) }\end{array}$ & 0.518 & 0.521 & $\mathbf{0 . 7 0 6}$ & -0.148 \\
\hline $\begin{array}{l}\text { Bodily Pain } \\
\text { (BP) }\end{array}$ & 0.517 & 0.515 & $\mathbf{0 . 7 0 2}$ & 0.146 \\
\hline $\begin{array}{l}\text { Physical } \\
\text { Function (PF) }\end{array}$ & 0.469 & 0.469 & $\mathbf{0 . 6 1 5}$ & -0.300 \\
\hline $\begin{array}{l}\text { Mental Health } \\
\text { (MH) }\end{array}$ & 0.777 & 0.782 & -0.135 & $\mathbf{0 . 8 7 4}$ \\
\hline Vitality & 0.787 & 0.796 & -0.184 & $\mathbf{0 . 8 7 3}$ \\
\hline $\begin{array}{l}\text { General Health } \\
\begin{array}{l}\text { Perception } \\
\text { (GHP) }\end{array}\end{array}$ & 0.466 & 0.455 & 0.432 & $\mathbf{0 . 5 1 8}$ \\
\hline $\begin{array}{l}\text { Social Function } \\
\text { (SF) }\end{array}$ & 0.013 & - & - & - \\
\hline
\end{tabular}

Collected data were entered and analysed using SPSS version 21. Descriptive statistics such as mean \pm standard deviation (SD) were calculated for quantitative variables. Frequency and percentages were calculated for categorical variables. For between the groups comparison of quantitative variables, t-test or one-way analysis of variance (ANOVA) were employed whereas Chi-square test or fisher exact test were categorical variables. A pvalue $\leq 0.05$ was taken as criteria for significance.

\section{RESULTS}

The baseline characteristics of the study participants are presented in Table 2. The mean age was $54.41 \pm$ 10.26 and more than half of the patients were of age more than 55 years. About $80.6 \%$ of the patients were males, $46 \%$ were diabetic, $67 \%$ were hypertensive, $12 \%$ had dyslipidemia and $22.4 \%$ were smokers. Approximately $58.7 \%$ of the patients had duration since PCI as 6 to 12 months and the mean duration since PCI was estimated as $16.66 \pm 14.97$ months. About $60.3 \%$ of the patients had STEMI and 55.2\% patients undergone for emergency PCI.

Table 2: Baseline demographic characteristics

\begin{tabular}{|l|c|}
\hline Characteristics & Total \\
\hline Total (N) & 433 \\
\hline Gender & $80.6 \%(349)$ \\
\hline Male & $19.4 \%(84)$ \\
\hline Female & $54.41 \pm 10.26$ \\
\hline Age (years) & $23.1 \%(100)$ \\
\hline 1st Quartile (26 to 48 years) & $22.9 \%(99)$ \\
\hline 2nd Quartile (48 to 55 years) & $25.4 \%(110)$ \\
\hline 3rd Quartile (55 to 61 years) & $28.6 \%(124)$ \\
\hline 4th Quartile (61 to 83 years) & \\
\hline Co-morbid & \\
\hline
\end{tabular}




\begin{tabular}{|l|c|}
\hline Diabetes & $46 \%(199)$ \\
\hline Hypertension & $67 \%(290)$ \\
\hline Dyslipidemia & $12 \%(52)$ \\
\hline Smoking & $22.4 \%(97)$ \\
\hline Duration since PCI (months) & $16.66 \pm 14.97$ \\
\hline 6 to 12 months & $58.7 \%(254)$ \\
\hline 13 to 24 months & $23.1 \%(100)$ \\
\hline$>24$ months & $18.2 \%(79)$ \\
\hline PCI indication & $60.3 \%(261)$ \\
\hline STEMI & $36.5 \%(158)$ \\
\hline NSTEMI & $3.2 \%(14)$ \\
\hline UA & $55.2 \%(239)$ \\
\hline Procedure type & $44.8 \%(194)$ \\
\hline Emergency & infarction, \\
\hline Elective elevation myocardial \\
NSTEMI=non-ST intervention, STEMI=ST elevation \\
PCI=percutaneous coronary ind \\
myocardial infarction, UA=unstable angina
\end{tabular}

The QOL assessment of all patients is summarized in Table 3. The highest mean score was reported for bodily pain $(73.8 \pm 19.7)$ followed by physical function $(61.7 \pm 24.3)$. After one year of procedure most of the patients rated their QOL as somewhat better $(52.9 \%)$ to much better $(24.7 \%)$. Overall physical component and mental component score were estimated as $50 \pm 23.3$ and $50 \pm 19.5$ respectively. Table 3 displays the stratified analysis of QOL with respect to gender. The male patients had significantly higher score for physical functioning, role limitations due to physical and functional problems as compared to similarly treated females $(\mathrm{p}<0.05)$. Whereas females had significantly higher score for vitality as compared to males $(\mathrm{p}<0.05)$. Overall physical health status was observed significantly better in males as compared to females $(\mathrm{p}<0.05)$ whereas overall mental health status was observed better in females compared to males $(\mathrm{p}<0.05)$.

Table 3: Quality of life assessment on eight domains of SF-36 by gender

\begin{tabular}{|l|c|c|c|c|}
\hline \multirow{2}{*}{ Total (N) } & \multirow{2}{*}{ Total } & \multicolumn{3}{|c|}{ Gender } \\
\cline { 3 - 5 } & 433 & Male & Female & P-value \\
\hline SF-36 Domains \\
\hline $\begin{array}{l}\text { General Health } \\
\text { Perception }\end{array}$ & $\begin{array}{c}59.1 \pm \\
22.8\end{array}$ & $\begin{array}{c}60 \pm \\
22.1\end{array}$ & $\begin{array}{c}55.4 \pm \\
25.2\end{array}$ & 0.233 \\
\hline $\begin{array}{l}\text { Physical } \\
\text { Function }\end{array}$ & $\begin{array}{c}61.7 \pm \\
24.3\end{array}$ & $\begin{array}{c}64.4 \pm \\
24.5\end{array}$ & $\begin{array}{c}50.7 \pm \\
20.1\end{array}$ & $<0.001^{*}$ \\
\hline Role Physical & $\begin{array}{c}55 \pm \\
36.7\end{array}$ & $\begin{array}{c}57.2 \pm \\
37.1\end{array}$ & $\begin{array}{c}46.1 \pm \\
33.9\end{array}$ & \multirow{2}{*}{$0.010^{*}$} \\
\hline Role Emotional & $\begin{array}{c}55 \pm \\
37.6\end{array}$ & $\begin{array}{c}57.9 \pm \\
37.6\end{array}$ & $\begin{array}{c}43.3 \pm \\
35.4\end{array}$ & \multirow{2}{*}{$0.001^{*}$} \\
\hline Social Function & $\begin{array}{c}55.6 \pm \\
14.4\end{array}$ & $\begin{array}{c}55.8 \pm \\
14.7\end{array}$ & $\begin{array}{c}54.9 \pm \\
13.3\end{array}$ & \multirow{2}{*}{0.683} \\
\hline Bodily Pain & $\begin{array}{c}73.8 \pm \\
19.7\end{array}$ & $\begin{array}{c}74.5 \pm \\
19.8\end{array}$ & $\begin{array}{c}70.9 \pm \\
19.4\end{array}$ & 0.157 \\
\hline Vitality & $\begin{array}{c}51.1 \pm \\
20.2\end{array}$ & $\begin{array}{c}50.1 \pm \\
20.5\end{array}$ & $\begin{array}{c}55.4 \pm \\
18.3\end{array}$ & \multirow{2}{*}{$0.030^{*}$} \\
\hline Mental Health & $\begin{array}{c}47.7 \pm \\
19.5\end{array}$ & $\begin{array}{c}47 \pm \\
19.6\end{array}$ & $\begin{array}{c}50.7 \pm \\
18.7\end{array}$ & \multirow{2}{*}{0.064} \\
\hline Quality of life compared to one year ago \\
\hline
\end{tabular}

\begin{tabular}{|c|c|c|c|c|}
\hline Much worse & $\begin{array}{l}2.1 \% \\
(9)\end{array}$ & $2 \%(7)$ & $2.4 \%(2)$ & \multirow{5}{*}{0.579} \\
\hline $\begin{array}{l}\text { Somewhat } \\
\text { worse }\end{array}$ & $\begin{array}{c}12.5 \% \\
(54)\end{array}$ & $\begin{array}{c}12.6 \% \\
(44)\end{array}$ & $\begin{array}{c}11.9 \% \\
(10)\end{array}$ & \\
\hline About the same & $\begin{array}{l}7.9 \% \\
(34)\end{array}$ & $\begin{array}{c}8.9 \% \\
(31)\end{array}$ & $3.6 \%(3)$ & \\
\hline $\begin{array}{l}\text { Somewhat } \\
\text { better }\end{array}$ & $\begin{array}{l}52.9 \% \\
(229)\end{array}$ & $\begin{array}{c}52.4 \% \\
(183)\end{array}$ & $\begin{array}{c}54.8 \% \\
(46)\end{array}$ & \\
\hline Much better & $\begin{array}{c}24.7 \% \\
(107)\end{array}$ & $\begin{array}{c}24.1 \% \\
(84)\end{array}$ & $\begin{array}{c}27.4 \% \\
(23)\end{array}$ & \\
\hline $\begin{array}{l}\text { Physical- } \\
\text { component } \\
\text { summary }\end{array}$ & $\begin{array}{l}50 \pm \\
23.3\end{array}$ & $\begin{array}{c}52.3 \pm \\
23.4\end{array}$ & $\begin{array}{c}40.6 \pm \\
20.6\end{array}$ & $<0.001 *$ \\
\hline $\begin{array}{l}\text { Mental- } \\
\text { component } \\
\text { summary }\end{array}$ & $\begin{array}{l}50 \pm \\
19.5\end{array}$ & $\begin{array}{l}49 \pm \\
19.5\end{array}$ & $54.1 \pm 19$ & $0.014^{*}$ \\
\hline
\end{tabular}

Table 4 displays the stratified analysis of QOL based on type of procedure. In elective procedure $30.9 \%$ of the patients rated their QOL as much better as compared to one year ago QOL, whereas, this proportion was only $19.7 \%$ for the patients who undergone emergency procedure. The relationship between QOL compared to one year ago and type of procedure was statistically significant $(\mathrm{p}<0.05)$. No statistically significant differences in mean score on all of the eight domains and two summary measures were observed $(p>0.05)$ with respect to age quartiles, type of procedure, and duration since PCI.

Table 4: Quality of life assessment on eight domains of SF-36 by type of procedure

\begin{tabular}{|c|c|c|c|}
\hline & \multicolumn{3}{|c|}{ Type of procedure } \\
\hline & Emergency & Elective & P-value \\
\hline Total (N) & 239 & 194 & - \\
\hline \multicolumn{4}{|l|}{ SF-36 Domains } \\
\hline $\begin{array}{l}\text { General Health } \\
\text { Perception }\end{array}$ & $59.5 \pm 23.5$ & $58.7 \pm 21.9$ & 0.450 \\
\hline $\begin{array}{l}\text { Physical } \\
\text { Function }\end{array}$ & $62.7 \pm 24.5$ & $60.5 \pm 24.1$ & 0.196 \\
\hline Role Physical & $56 \pm 37.7$ & $53.9 \pm 35.5$ & 0.514 \\
\hline Role Emotional & $55.5 \pm 37.3$ & $54.5 \pm 38.2$ & 0.786 \\
\hline Social Function & $54.6 \pm 14.2$ & $56.9 \pm 14.6$ & 0.137 \\
\hline Bodily Pain & $73.3 \pm 19.5$ & $74.4 \pm 20.1$ & 0.612 \\
\hline Vitality & $49.7 \pm 20.3$ & $52.9 \pm 19.9$ & 0.075 \\
\hline Mental Health & $47.2 \pm 19.6$ & $48.4 \pm 19.3$ & 0.996 \\
\hline \multicolumn{4}{|c|}{ Quality of life compared to one year ago } \\
\hline Much worse & $2.1 \%(5)$ & $2.1 \%(4)$ & \multirow{5}{*}{$0.031 *$} \\
\hline $\begin{array}{l}\text { Somewhat } \\
\text { worse }\end{array}$ & $15.5 \%(37)$ & $8.8 \%$ (17) & \\
\hline About the same & $9.2 \%(22)$ & $6.2 \%(12)$ & \\
\hline $\begin{array}{l}\text { Somewhat } \\
\text { better }\end{array}$ & $53.6 \%(128)$ & $\begin{array}{c}52.1 \% \\
(101)\end{array}$ & \\
\hline Much better & $19.7 \%(47)$ & $30.9 \%(60)$ & \\
\hline $\begin{array}{l}\text { Physical- } \\
\text { component } \\
\text { summary }\end{array}$ & $50.6 \pm 24.2$ & $49.2 \pm 22.3$ & 0.500 \\
\hline $\begin{array}{l}\text { Mental- } \\
\text { component } \\
\text { summary }\end{array}$ & $49 \pm 19.2$ & $51.2 \pm 19.8$ & 0.403 \\
\hline
\end{tabular}


Trended relationship between quality of life assessments scores and patients' perception of quality of life compared to one year ago is presented in Figure 2. A significant increasing trend, with respect to patients' perception of quality of life compared to one year ago, was observed on five out of eight domains namely general health perception (GHP), physical function (PF), role physical (RP), role emotional (RE), and bodily pain (BP). The mean scores for patients who rated their quality of life "much worse" and "much better" compared to one year ago were $40.2 \pm$ 20.9 vs. $61.4 \pm 20.1 ; \mathrm{p}<0.001,43.9 \pm 32.3$ vs. $68 \pm$ $28.3 ; \mathrm{p}=0.005,16.7 \pm 35.4$ vs. $64.7 \pm 33.6 ; \mathrm{p}<0.001$, $29.6 \pm 38.9$ vs. $59.5 \pm 38.6 ; \mathrm{p}=0.001$, and $42.7 \pm 21.1$ vs. $79.9 \pm 18.5 ; \mathrm{p}<0.001$ on GHP, PF, RP, RE, and BP domains respectively. The mean scores on social function (SF) and mental health (MH) domains were found to be not related to the patients' perception of quality of life compared to one year ago, while, there was a decreasing trend on vitality domain.

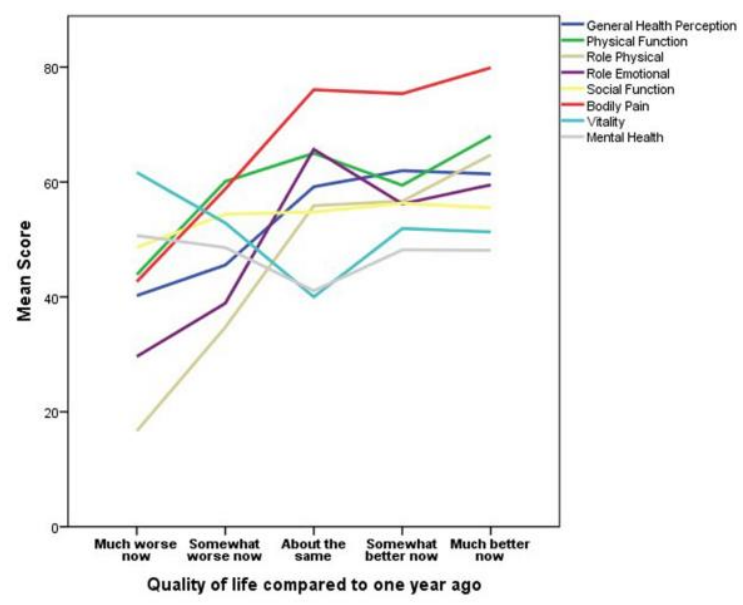

Figure 2: Trends in quality of life assessment scores with respect to patients' perception of quality of life compared to one year ago

\section{DISCUSSION}

HRQOL of life is perceived to be a significant concern in order to see the efficacy of multiple interventions, treatment, and health policies, the establishment of health services and the strengthening of the relationship between patients and physicians. In other words, HRQOL improvement is one of the targets of treatment in the different fields of medicine. Therefore, the current study aimed to assess the HRQOL among CAD patients post PCI using SF-36.

Various type of studies have shown that PCI enhances the HRQOL and exercise capacity when compared with before PCI status. ${ }^{1,4,9-13}$ In a study Pocock et al. showed that after one year of PCI, 33\% of the patients rated their life as much better. ${ }^{14}$ Weintraub et al. also observed that mean QOL score significantly improved at six, twelve, twenty four, and thirty six months among patients who underwent PCI. ${ }^{13}$ Cohen et al. in their study randomized patients to $\mathrm{CABG}$ and $\mathrm{PCI}$ and found that mean QOL in PCI significantly improved by $30 \%$ at six and twelve months. ${ }^{15}$ Similarly in the present, we found that $77.6 \%$ of the patients rated their life as somewhat better to much better compared to one year before QOL.

In the present study, majority of the patients were males and had higher scores for all SF-36 domains except vitality. It was also observed that overall physical health status of men was better than women who underwent PCI. Literature also support these findings that QOL is better in males than females who underwent same PCI procedure. ${ }^{16-18}$ Uchmanowicz et al. also found that female patients scored lesser than males in all domains of SF-36. ${ }^{19}$ It may be due to the fact that females are at greater risk recurrent angina post PCI as compared to males..$^{20}$

No disparity in QOL was observed in the present analysis with respect to various age quartiles. Similarly, various studies have shown that elder and younger patients showed improved QOL after PCI and proportion of improved QOL in both groups was similar or elder patients showed better QOL relative to younger patients, even with greater risk profiles at baseline. ${ }^{10,12,21,22}$ In the SYNTAX trial consisting of patients of age $<75$ years and $>75$ years, no statistically significant difference was observed in QOL subscales at 6 or 12 months after PCI. ${ }^{15}$

Emergency PCI is greatly influenced by the adverse health characteristics of patients rather than the intervention itself. It is also considered as one of the significant predictor of mortality. ${ }^{23}$ In our study, $55.2 \%$ of the patients underwent for emergency PCI and $44.8 \%$ underwent for elective PCI and we found majority of the patients who underwent elective procedure rated their QOL as much better as compared to one year ago QOL. Therefore, planned and elective PCI have better health outcomes, with reduced risk of restenosis and major adverse cardiac events. ${ }^{24}$

Few limitations of the present study were that the sample was recruited from a single center using nonprobability of a consecutive sampling method, which may lead to a lack of generalizability of findings. Future prospective and multi-center studies should be conducted. In addition, this study involved patients with a period of at least 6 months after PCI. In future research, the long-term impact of PCI on QOL should 
be measured as well as the significant predictors of poor QOL.

\section{CONCLUSION}

Improved quality of life, compared to a year ago, is reported by most of the patients. An acceptable (>50) mean score was observed on most of the quality-of-life domains of SF-36 and it was found to be positively related to the patient stated degrees of quality of life. Physical health status was observed significantly better in males as compared to females whereas the mental health status was observed better in females.

\section{AUTHORS' CONTRIBUTION:}

RK, TS, JS, and MK: Concept and design, data acquisition, interpretation, drafting, final approval, and agree to be accountable for all aspects of the work. JAS, AA, AK, AHS, LR, AH, and DK: Data acquisition, interpretation, drafting, final approval and agree to be accountable for all aspects of the work.

Conflict of interest: Authors declared no conflict of interest.

Acknowledgment: The authors wish to acknowledge Mr. Mudasir Zaidi and Mrs. Kiran Fatima for their support in translating English version of questionnaire to local language (Urdu).

\section{REFERENCES}

1. Jamee Shahwan A, Abed Y, Desormais I, Magne J, Preux PM, Aboyans V, et al. Epidemiology of coronary artery disease and stroke and associated risk factors in Gaza community -Palestine. PLoS One. 2019;14(1):e0211131.

2. Sanchis-Gomar F, Perez-Quilis C, Leischik R, Lucia A. Epidemiology of coronary heart disease and acute coronary syndrome. Ann Transl Med. 2016;4(13):256.

3. Gierlaszyńska K, Pudlo R, Jaworska I, Byrczek-Godula K, Gąsior M. Tools for assessing quality of life in cardiology and cardiac surgery. Kardiochir Torakochirurgia Pol. 2016;13(1):78-82.

4. Fatima K, Yousuf-Ul-Islam M, Ansari M, Bawany FI, Khan MS, Khetpal A, et al. Comparison of the Postprocedural Quality of Life between Coronary Artery Bypass Graft Surgery and Percutaneous Coronary Intervention: A Systematic Review. Cardiol Res Pract. 2016;2016:7842514.

5. Rathod KS, Koganti S, Iqbal MB, Jain AK, Kalra SS, Astroulakis $\mathrm{Z}$, et al. Contemporary trends in cardiogenic shock: Incidence, intra-aortic balloon pump utilisation and outcomes from the London Heart Attack Group. Eur Heart J Acute Cardiovasc Care. 2018;7(1):16-27.

6. Tully PJ. Quality-of-Life measures for cardiac surgery practice and research: a review and primer. J Extra Corpor Technol. 2013;45(1):8-15.

7. Mahesh PKB, Gunathunga MW, Jayasinghe S, Arnold SM, Haniffa R, De Silva AP. Pre-event quality of life and its influence on the post-event quality of life among patients with ST elevation and non-ST elevation myocardial infarctions of a premier province of Sri Lanka. Health Qual Life Outcomes. 2017;15(1):154.

8. Lins L, Carvalho FM. SF-36 total score as a single measure of health-related quality of life: Scoping review. SAGE Open Med 2016;4:2050312116671725

Address for Correspondence:

Dr. Rajesh Kumar, Assistant Professor of Cardiology at National Institute of Cardiovascular Diseases (NICVD), Karachi, Pakistan.

Email: rajeshnarsoolal@gmail.com
9. Ware ME, Kosinski M, Dewey JE. How to score version 2 of the SF-36 health survey (standard \& acute forms): Quality Metric Incorporated; 2001.

10. Grantham JA, Jones PG, Cannon L, Spertus JA. Quantifying the early health status benefits of successful chronic total occlusion recanalization: Results from the FlowCardia's Approach to Chronic Total Occlusion Recanalization (FACTOR) Trial. Circ Cardiovasc Qual Outcomes. 2010;3(3):284-90.

11. Lowe HC, Oesterle SN, He KL, Macneill BD, Burkhoff D. Outcomes following percutaneous coronary intervention in patients previously considered "without option": a subgroup analysis of the PACIFIC Trial. J Interv Cardiol. 2004;17(2):87-91.

12. Spertus JA, Salisbury AC, Jones PG, Conaway DG, Thompson RC. Predictors of quality-of-life benefit after percutaneous coronary intervention. Circulation. 2004;110(25):3789-94.

13. Weintraub WS, Spertus JA, Kolm P, Maron DJ, Zhang Z, Jurkovitz C, et al. Effect of PCI on quality of life in patients with stable coronary disease. N Engl J Med. 2008;359(7):677-87.

14. Pocock SJ, Henderson RA, Clayton T, Lyman GH, Chamberlain DA. Quality of life after coronary angioplasty or continued medical treatment for angina: three-year follow-up in the RITA-2 trial. Randomized Intervention Treatment of Angina. J Am Coll Cardiol. 2000;35(4):907-14.

15. Cohen DJ, Van Hout B, Serruys PW, Mohr FW, Macaya C, den Heijer P, et al. Quality of life after PCI with drug-eluting stents or coronary-artery bypass surgery. N Engl J Med. 2011;364(11):1016-26.

16. de Quadros AS, Lima TC, Rodrigues AP, Modkovski TB, Welter DI, Sarmento-Leite R, et al. Quality of life and health status after percutaneous coronary intervention in stable angina patients: results from the real-world practice. Catheter Cardiovasc Interv. 2011;77(7):954-60.

17. Oreel TH, Nieuwkerk PT, Hartog ID, Netjes JE, Vonk ABA, Lemkes J, Laarhoven HWM, et al. Gender differences in quality of life in coronary artery disease patients with comorbidities undergoing coronary revascularization. PLoS One. 2020;15(6):e0234543.

18. Koh Y, Stehli J, Martin C, Brennan A, Dinh DT, Lefkovits J, Zaman. Does sex predict quality of life after acute coronary syndromes: an Australian, state-wide, multicentre prospective cohort study. BMJ Open. 2019;9(12):e034034.

19. Uchmanowicz I, Łoboz-Grudzień K. Factors influencing quality of life up to the 36th month follow-up after treatment of acute coronary syndrome by coronary angioplasty. Nur Res Rev. 2015;5:21-3.

20. Gierszewska K, Jaworska I, Skrzypek M, Gąsior M, Pudlo R. Quality of life in patients with coronary artery disease treated with coronary artery bypass grafting and hybrid coronary revascularization. Cardiol J. 2018;25(5):621-7.

21. Guo L, Hai-Chen Lv, Huang RC. Percutaneous Coronary Intervention in Elderly Patients with Coronary Chronic Total Occlusions: Current Evidence and Future Perspectives. Clin Interv Aging. 2020;15:771-81.

22. Kaambwa B, Gesesew HA, Horsfall M, Chew D. Quality of Life Changes in Acute Coronary Syndromes Patients: A Systematic Review and Meta-Analysis. Int J Environ Res Public Health. 2020;17(18):6889.

23. Rahman N, Hussain B, Artani A. Outcomes of Left Main Percutaneous Coronary Intervention. J Coll Physicians Surg Pak. 2019;29(6):498.

24. Patel DB, Shah R, Jovin I. Improving outcomes of percutaneous coronary interventions in patients with stable ischemic heart disease. J Thorac Dis. 2020;12(4):1740-9. 